\title{
VIOLÊNCIA NA ESCOLA E CONTRA A ESCOLA: UM ESTUDO A PARTIR DAS PERCEPÇÕES DE PROFESSORES E DIRETORES DAS ESCOLAS PÚBLICAS DO ENSINO FUNDAMENTAL DA REGIÃO SUL DO BRASIL*
}

\author{
Giordani A. Colvora** \\ Marcos R. dos Santos ${ }^{* * *}$ \\ Erni J. Seibel ${ }^{* * * *}$
}

Resumo: O presente trabalho tem por objetivo apresentar os principais resultados das questões sobre violência nas escolas públicas de ensino fundamental percebidas por professores e diretores das escolas por ocasião da Prova Brasil 2007. Os questionários foram respondidos por 55.462 profissionais da educação, sendo 47.306 professores (4as. e 8as. séries) e 8.156 diretores. Foram feitas 39 perguntas aos diretores e 27 aos professores. Os questionários respondidos contemplam inúmeras perguntas sobre violência no ambiente escolar e suas várias formas (atentado, furto, roubo, depredação, pichação, sujeira, consumo e tráfico de drogas). Neste artigo selecionamos aquelas questões cujas respostas indicavam situações de maior preocupação de professores e diretores. O desmembramento geográfico, administrativo e institucional dos dados permite capturar as diferenças mais acentuadas desta questão, assim como sugerir a direção em que a atenção pública deve ser diferenciada na forma das políticas de segurança escolar.

Palavras-chave: Violência nas escolas. Prova Brasil. Políticas de Segurança Pública. 
Abstract: The present work has for objective to present the main results of the questions on violence in the Public Schools of the Basic Education Level perceived by professors and directors of the schools for occasion of the test Prova Brazil 2007. The questionnaires had been answered by 55.462 professionals of the Education, being 47.306 professors (4as. e 8as. series) and 8.156 directors. 39 questions to directors and 27 to the professors had been made. The answered questionnaires contemplate innumerable questions on violence in the Schools environment and its different forms (attempted against, robery, robbery, depredation, dirt, consumption and I traffic of drugs). In this article we select those questions whose answers indicated situations of bigger concern of professors and directors. The geographic, administrative and institucional dismemberment of the data allows to perceive the accented differences of this problem, as well as suggesting the direction where the public attention must be differentiated in the form of the politics of school security.

Keywords: Violence in the schools. Prova Brasil. Politics of Public Security. 


\section{Introdução}

Furtos de lapiseira, roubos de celulares, pontapés, empurrões, xingamentos; brincadeirinhas, bullying, depredações da escola, pichações, socos, perfurações corporais, presença de armas de fogo, gangues, ameaças à vida, tráfico de drogas e morte, dentre outros. Trata-se de fenômenos que também passaram a se manifestar no intramuros das escolas brasileiras, bem como em outras partes da aldeia global. Acontecimentos completamente diversos em si, com capacidades distintas de impactar a coesão social, com consequências bastante diversas tanto para quem comete, quanto para quem sofre, mas que são postas sob um mesmo conceito, demasiadamente amplo e possivelmente incapaz de pormenorizar suas especificidades.

Neste trabalho vamos abordar uma dimensão restrita da questão da violência nas escolas, porém ampla na sua base de dados. Nossa proposta é mostrar a experiência vivida na percepção de professores e diretores das escolas públicas (municipais e estaduais) do ensino fundamental dos estados do Paraná, Santa Catarina e Rio Grande do Sul. A base de dados é os questionários respondidos por professores e diretores por ocasião da Prova Brasil 2007. Estes contemplam inúmeras perguntas sobre violência no ambiente escolar e suas várias formas (atentado, furto, roubo, depredação, pichação, sujeira, consumo e tráfico de drogas). Os professores e diretores respondentes dos três estados totalizam 47.306 e 8.156, respectivamente (veja quadro 1 ).

A possibilidade de registrar dados de larga escala sobre o tema é outro ponto de destaque neste trabalho, considerando que a produção deste tipo de informação e conhecimento sempre foi bas- 
tante restrita a estudos de caso ou pesquisa com dados de baixa escala. A cobertura dos três estados do Sul do País é um recorte original do projeto de pesquisa. ${ }^{1}$ Outros trabalhos já recortaram os dados da temática para as microrregiões de Santa Catarina (vide COLVARA, 2011). Nos limitamos aqui a apresentar apenas os dados que tiveram proporções percentuais mais elevadas dos perceptores.

\section{Aspectos conceituais}

Na tentativa de definir o fenômeno "violência no cotidiano escolar", pesquisadores buscam termos adequados para definir o fenômeno da violência. Alguns autores preferem tratar sociologicamente como violentia apenas os atos tipificados nos respectivos Códigos Penais, cuja legislação impõe sanções como detenção ou reclusão; medidas restritivas de liberdade, normalmente tidas como violências duras, restringindo as pesquisas somente aos aspectos mais graves. Em contrapartida, Bourdieu e Passeron (1982) reconhecem a existência da violência simbólica no ato de impor significados culturais como verdadeiros, mas que, no entanto, são arbitrários, compondo o capital simbólico das classes dominantes, o que nos leva ao encontro de outra possível forma de violência: aquela cometida pela própria instituição de ensino.

Entre esses dois extremos há inúmeras outras definições que são costumeiramente alardeadas, com slogans sensacionalistas que apregoam a política da tolerância zero, típicas da sociedade do espetáculo já visualizada pelas teorias do sociólogo Eric Debardieux, destacando o campo midiático e incrementando com 
seu costumeiro alarde o multifacetado fenômeno das violências que ocorrem nas escolas, espaço outrora sacralizado que agora se torna profano e cujas crianças inocentes acabam sendo vítimas de monstros perversos, expondo as famílias a um permanente clima de intranquilidade; isso quando não resolve imputar aos alunos características bestiais, criminalizando a juventude e colocando-os em um status que exige um permanente controle, que deve ser exercido pelos adultos que controlam o Estado, a sociedade civil e também as escolas.

O processo de democratização da educação, desenvolvido no contexto brasileiro a partir da década de 1990 e que adentra até os dias atuais, contribuiu, de acordo com Portela (2006), para a universalização do acesso ao ensino fundamental. A escola, que anteriormente era tida como um lócus socialmente restrito, passou a agregar alunos de distintas classes sociais, idades e culturas, ampliando seu alcance em busca da redução dos alarmantes índices de analfabetismo que o País convivia no início da década, colocando lado a lado nas carteiras escolares uma diversidade social outrora inexistente. Clima propício ao conflito, não obstante o inegável ganho social da inclusão (SPOSITO, 2002).

De acordo com Zaluar (2007), as transformações promovidas com a implantação de políticas educacionais na década de 1990 coincidiram com as novas expectativas que a sociedade brasileira gerou por ocasião da abertura democrática, no que tange à empregabilidade dos jovens, ao exercício da cidadania e às liberdades civis trazidas pela Constituição Federal de 1988, mas que, no entanto, não se transformaram em direitos de fato, causando uma explosão da violência em todo o País, aceleradas pelo sucateamento do poder judiciário e da redução da autoridade policial. 
Segundo Zaluar (2011), a disseminação do “crime-negócio" e da "economia subterrânea" motivou inúmeros jovens a optar pelo caminho do crime, notoriamente muito mais lucrativo do que as ofertas do mercado de trabalho. Portanto, o fracasso da democracia inacabada estava diretamente ligado ao fracasso da segurança pública. Sabidamente, nem só o crime-negócio faz vítimas nas escolas; há também fatores de ordem individual, segundo Farrington (2002), como os familiares e os relativos à vulnerabilidade social do bairro. Há também os relativos aos riscos e as escolhas trazidas pela modernidade, como a construção da identidade, os valores trazidos pela sociedade pós-tradicional, a insegurança ontológica e a desintegração dos laços humanos (GIDDENS, 2002), que muitas vezes deslocam seu comportamento, levando-os agir em seu éthos guerreiro, ligados às relações de poder entre grupos, que não necessariamente tenham relações alguma com o crime-negócio, tampouco com reivindicações políticas revolucionárias, levando-os a estar junto à toa, muitas vezes identificando-se com a linguagem da violência (MAFFESOLI, 2000).

Indubitavelmente, o fenômeno da violência escolar existe, e hoje têm contornos mais diversos do que há duas décadas (CHARLOT, 2002). Abramovay (2005), Sposito (2002), entre outros pesquisadores, apontaram a magnitude da questão, que faz parte da agenda pública europeia (DEBARDIEUX, 2002), constituindo-se um desafio para os educadores modernos do mundo todo.

Os perigos da violência do meio escolar são inúmeros: geram abandono escolar precoce, estão fortemente associados à rotatividade e absenteísmo dos professores e alunos, e ao clima escolar (COLVARA, 2011). Além disso, geram mortes, graves danos físicos e, principalmente, psicológicos, estando ligados a crimes, transgressões e incivilidades, na definição de Charlot (2002). 


\section{Metodologia}

Como já esclarecemos, processamos aqui os questionários preenchidos por professores e diretores por ocasião da Prova Brasil 2007. ${ }^{2}$ O questionário diretores contempla 39 perguntas sobre o tema e o professores, 27. As perguntas são fechadas e todas indicam o envolvimento de possíveis agressores internos (alunos, professores e funcionários) e externos, em várias modalidades de violência. Os questionários não possibilitam executar uma chave de tal forma a associar escola, alunos, professor e diretor. Ao mesmo tempo que esta é uma limitação para a pesquisa, é uma forma de proteção ética aos grupos sociais envolvidos.

As pesquisas de caráter quantitativo e de larga escala apresentam, por um lado, restrições quanto à explicitação de aspetos subjetivos do tema, mas tem, por outro lado, como atributo positivo a universalização dos dados. Conforme podemos conferir no quadro 1, estamos apresentando os resultados dos questionários respondidos por 55.462 profissionais da educação (professores das 4as. e 8as. séries das escolas públicas de ensino fundamental da região Sul).

Quadro 1

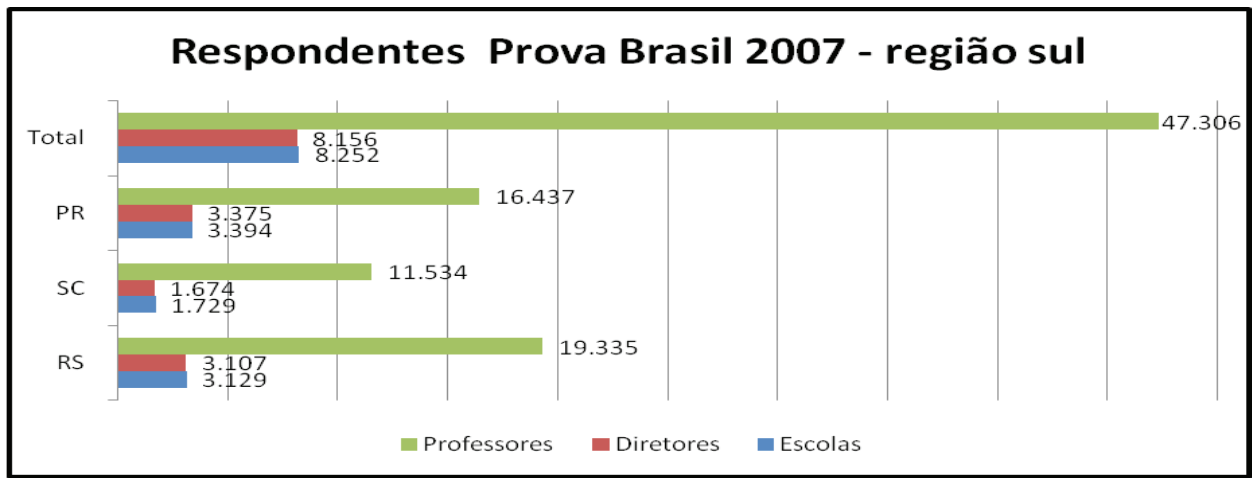

Fonte: INEP/NIPP.

\section{Análise dos dados}


Como já afirmamos, restringimos, primeiramente, a apresentação dos resultados às perguntas que apresentaram resultados significativos e, em segundo, porque a exposição de todos os gráficos tornaria muito extenso este artigo. ${ }^{3} \mathrm{~A}$ seguir apresentaremos os gráficos mais relevantes das respostas do professores e em seguida dos diretores.

O gráfico 1 aponta que a mais significativa forma de agressão a professores por parte dos alunos foi a verbal, tendo sido também registrada agressão física (entre 7,0\% e 9,0\%). É de ser registrar também agressão verbal entre professores (entre 9,8\% e 13,9\%).

Gráfico 1 - Professores

NESTE ANO, HOUVE Agressão verbal a professores. - POR PARTE DE ALUNO

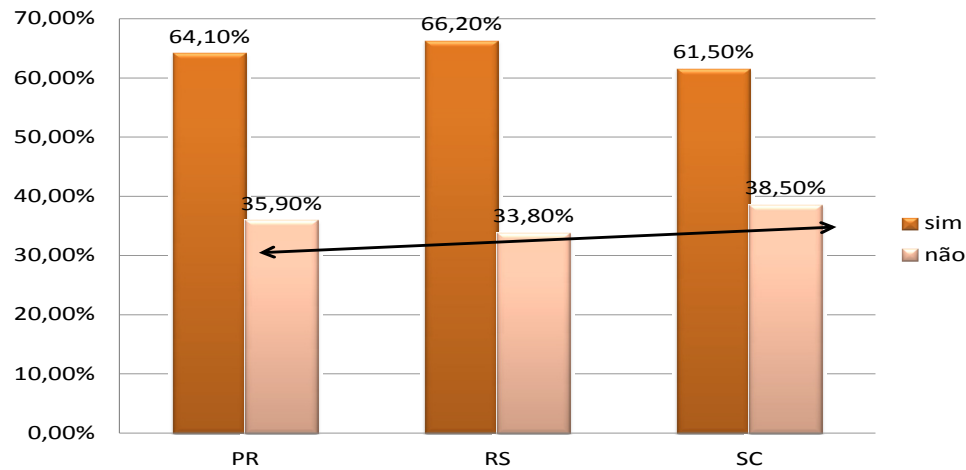

Fonte: Prova Brasil 2007/NIPP.

O gráfico 2 é fortemente revelador de agressões aluno-aluno, de acordo com os professores. Destacamos a diferença entre os estados, sendo o Rio Grande do Sul com maior índice de agressão. Este resultado indica que possa haver também uma grande diversidade regional no interior dos estados, assim como ocorrências 
diferenciadas por dependência administrativa da escola (municipal, estadual ou federal).

\section{Gráfico 2 - Professores}

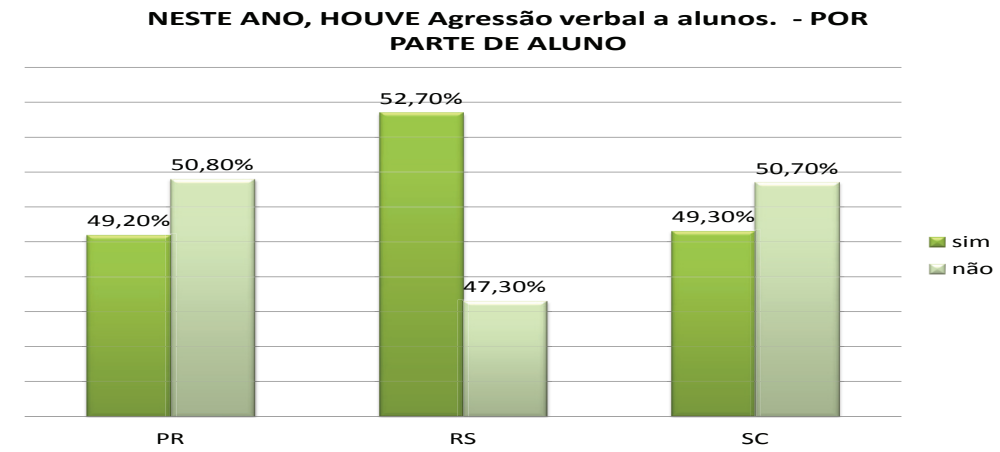

Fonte: Prova Brasil 2007/NIPP.

Quase na mesma proporção de agressão verbal está a agressão física aluno-aluno, no entanto as diferenças estaduais não são tão significativas.

\section{Gráfico 3 - Professores}

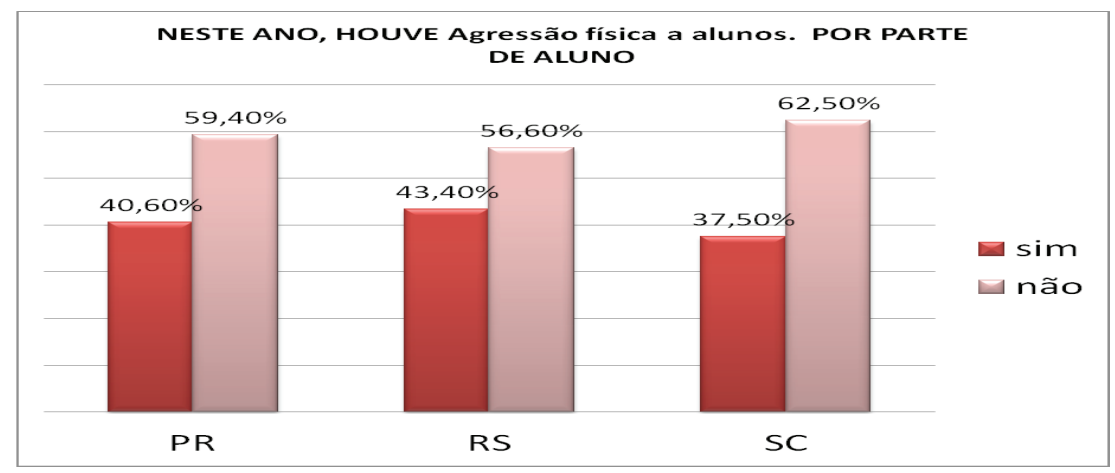

Fonte: Prova Brasil 2007/NIPP. 
O Gráfico 4 é praticamente um registro de ocorrência, pois remete a fatos ocorridos com os professores enquanto ministravam aulas. No Paraná o índice de agressão foi um pouco mais elevado.

Gráfico 4 - Professores

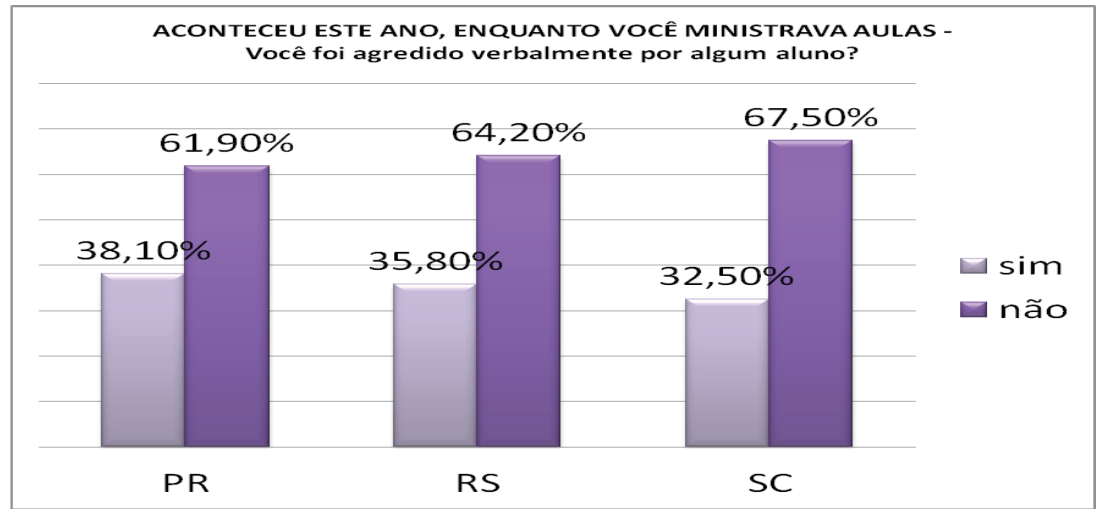

Fonte: Prova Brasil 2007/NIPP.

Apesar da semelhança nas perguntas feitas a professores e diretores, as percepções destes foram mais significativas em aspectos relacionados à escola como um todo, como depredações, pichações, roubo ou furto, uso ou tráfico de drogas (gráficos 5, 6 e 7). Chama a atenção o grande percentual (até 46\%) de respostas missing dos diretores quando a pergunta remetia a agressão, roubo ou furto cometidos por agentes internos (alunos, professores ou funcionários). Talvez este aspecto possa ser explicado pelo constrangimento dos diretores, importância aos fatos ou até a desinformação. Mesmo assim, os gráficos 6 e 7 indicam furto e pichação por membros de dentro da escola. 
VIOLÊNCIA NA ESCOLA E CONTRA A ESCOLA: UM ESTUDO A PARTIR DAS PERCEPÇÕES

DE PROFESSORES E DIRETORES DAS ESCOLAS PÚBLICAS DO ENSINO FUNDAMENTAL DA REGIÃO SUL DO BRASIL

Gráfico 5 - Diretores

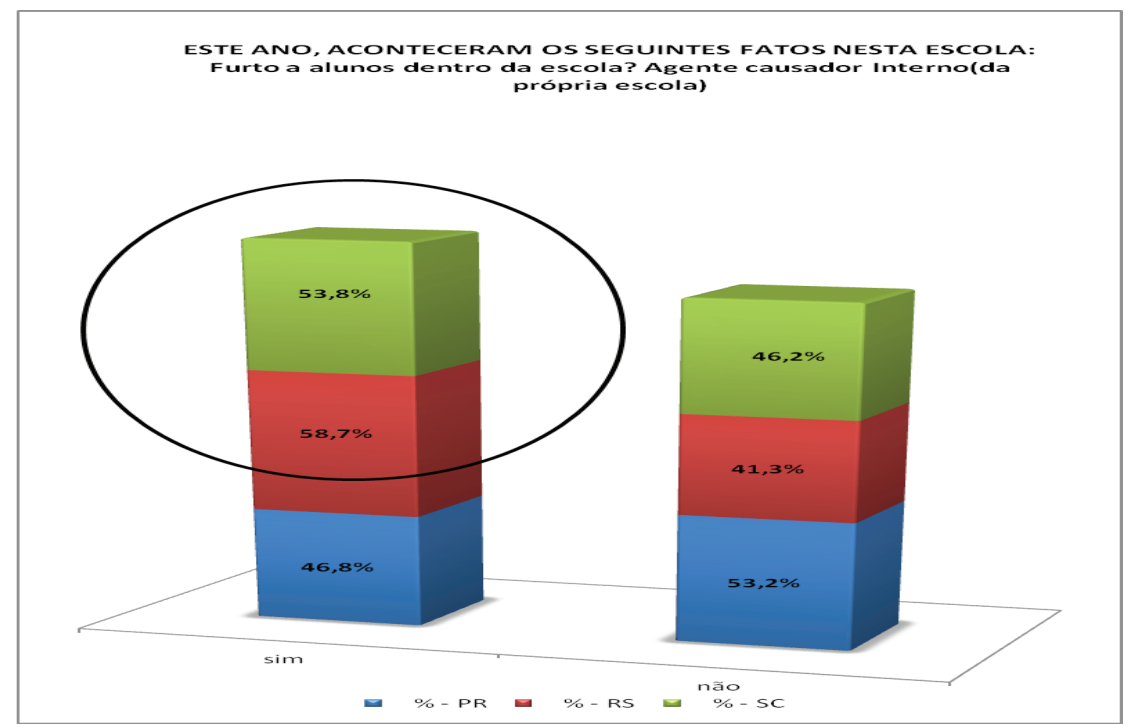

Fonte: Prova Brasil 2007/NIPP.

\section{Gráfico 6 - Diretores}

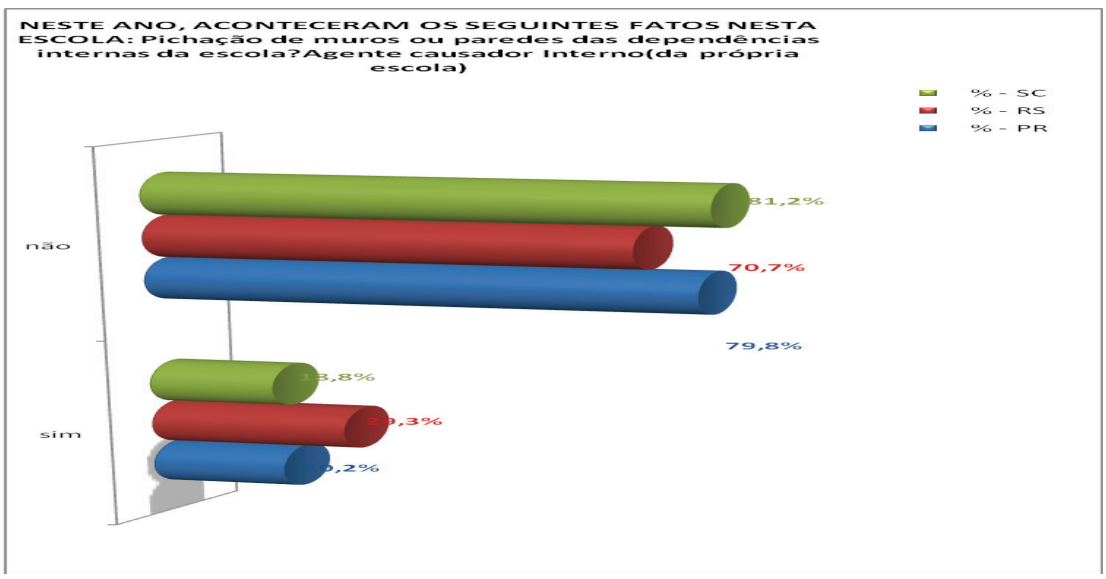

Fonte: Prova Brasil 2007/NIPP.

Os gráficos 7 e 8 indicam um problema que atinge de forma mais direta o diretor da escola: o consumo e tráfico de drogas; nes- 
GIORDANI A. COLVORA

MARCOS R. DOS SANTOS

ERNI J. SEIBEL

te caso, os agentes externos foram os dados mais significativos, com maior destaque para o Rio Grande do Sul em ambos os casos.

\section{Gráfico 7 - Diretores}

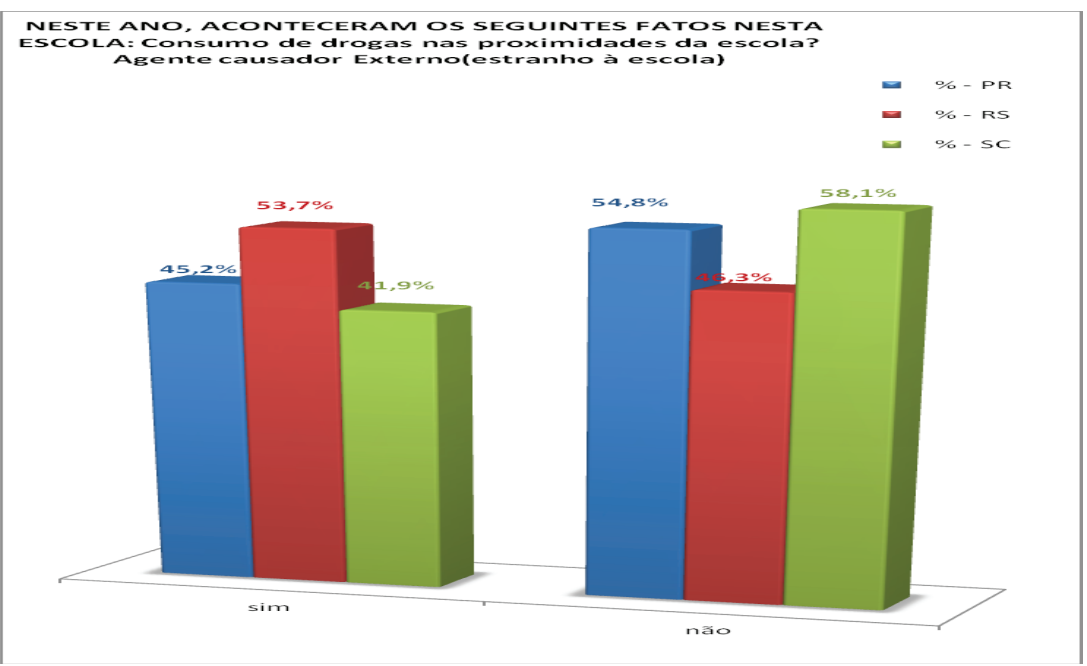

Fonte: Prova Brasil 2007/NIPP.

Gráfico 8 - Diretores

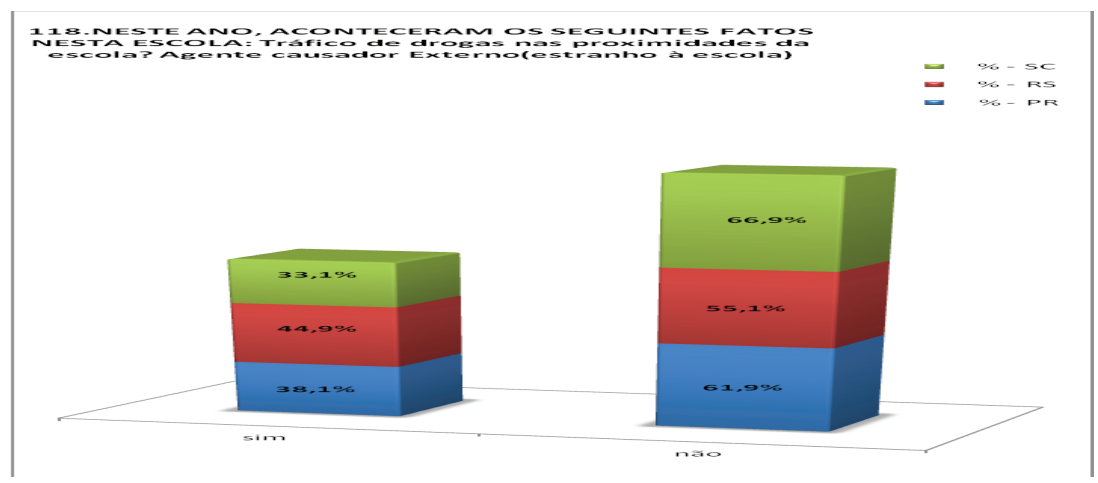

Fonte: Prova Brasil 2007/NIPP. 


\section{Considerações finais}

O fenômeno da violência nas escolas suscita, entre outros questionamentos, o próprio papel das escolas no processo educacional ou civilizatório, de controlar ou reduzir o éthos guerreiro de seus alunos e, se, com quais medidas? Qual a medida certa entre permissividade, claramente nociva à convivência social e que pode gerar inúmeras vítimas nas escolas, e a ditadura dos adultos, em controlar mentes e corpos dos alunos, negando seus próprios significados, sem dar-lhes as oportunidades esperadas, tampouco a cidadania desejada?

Certamente, a resposta não passa pela instalação de câmaras de vigilância, utilização do aparato policial nas escolas, manutenção do currículo conservador, ampliação da punição dos alunos, aumento dos gastos públicos com catracas eletrônicas, equipamentos de raio- $x$, e construção de muros e grades que por vezes aproximam os estabelecimentos de ensino a presídios.

Deve-se reconhecer que parte das incivilidades e transgressões que ocorrem vêm de uma linguagem específica dos jovens, cujo sentido da ação social nada tem a ver com o que normalmente é percebido pelos adultos. Acusam-nos de marginais, quando muitas vezes estão expressando uma linguagem de grupo, típicas da juventude, entre companheiros de classe. Se possível, deve-se estimular o uso das agressividades para as artes, esportes, dentre outras formas de manifestações, mas saber que, ao convivermos com seres humanos, a violência é algo que está presente como constituinte das relações, devendo ser aceita em certos níveis.

Uma pesquisa de larga escala não se propõe à exatidão de dados e ao resgate de subjetividades dos fenômenos que analisa. Os resultados de uma pesquisa desta natureza indicam a proporção dos 
fenômenos e os estudos comparativos, temporais e espaciais possibilitam, a partir de uma sustentação teórica produzir hipóteses, aí sim para pesquisa de natureza qualitativa.

Os resultados desta pesquisa indicam uma predominância de atos de violência, principalmente de agressão verbal e física, nas direções aluno-aluno e aluno-professor, bem como uma forte proporção de atitudes e ações perpassadas por drogas a partir de agentes externos às escolas. Em alguns casos, as diferenças entre os três estados foram bastante acentuadas. O desmembramento de recorte geográfico, administrativo e institucional dos dados permite capturar as diferenças mais acentuadas desta questão, assim como sugerir a direção em que a atenção pública deve ser diferenciada na forma das políticas de segurança escolar.

\section{Referências}

ABRAMOWAY, M. Cotidiano das escolas entre violências. Brasília: Unesco, 2005.

BORDIEU, P.; PASSERON, J. C. A reprodução: elementos para uma teoria do sistema de ensino. 2. ed. Rio de Janeiro: Francisco Alves, 1982.

CHARLOT, Bernard. A violência nas escolas: como os sociólogos franceses abordam essa questão. Sociologias, Porto Alegre, ano 4, n. 8., 2002. Disponível em: <www.scielo.com>. Acesso em: 12 dez. 2011.

COLVARA, G. A. As escolas, os muros e a rua: a violência nas escolas públicas catarinenses na percepção dos diretores. 2011. Monografia (Trabalho de Conclusão de Curso) - Universidade Federal de Santa Catarina, 2011.

DEBARDIEUX, E. Violência nas escolas: divergências sobre palavras e um desafio político. In: BLAYA, C.; DEBARBIEUX, E. (Orgs.). Violência nas escolas e políticas públicas. Brasília: Unesco, 2002. 
DEVINE, J. A mercantilização da violência escolar. In: BLAYA, C.; DEBARBIEUX, E. (Orgs.). Violência nas escolas e políticas públicas. Brasília: Unesco, 2002.

FARRINGTON, David P. Fatores de Risco para a Violência Juvenil. In: BLAYA, C.; DEBARBIEUX, E. (Orgs.). Violência nas escolas e políticas públicas. Brasília: Unesco, 2002.

GIDDENS, Anthony. Modernidade e Identidade. Rio de Janeiro: Jorge Zahar, 2002.

MAFFESOLI, M. O Tempo das tribos: declínio do individualismo nas sociedades de massa. Rio de Janeiro: Forense, 2000.

PORTELA, Romualdo. Da universalização do ensino fundamental ao desafio da qualidade: uma análise histórica. Educ. Soc., Campinas, v. 28, 2006. Disponível em: <http://www. scielo.br>. Acesso em: 20 out. 2011.

SPOSITO, Marilia Pontes (Coord.). Juventude e escolarização (19801998). Brasília: MEC/INEP/Comped, 2002.

ZALUAR, Alba. Democratização inacabada. Fracasso da segurança pública. Estudos avançados, n. 23, 2007.

Paradoxos da proibição. Jornal dos Economistas, Rio de Janeiro, p. 3-4, 2011. 


\section{Notas}

* Este trabalho é um dos resultados do Projeto Análise e Avaliação dos Indicadores Educacionais da Região Sul, projeto aprovado pelo edital OBEDUC 2010, Capes/INEP.

** Bacharel em Ciências Sociais e pesquisador do Núcleo Interdisciplinar em Políticas Públicas (NIPP). E-mail: <giordanicolvara@hotmail.com>.

*** Bacharel em Ciências Sociais e bolsista no Projeto Observatório da Educação no Núcleo Interdisciplinar de Políticas Públicas (NIPP/UFSC). E-mail: $<$ marcospiquiri@yahoo.com.br>.

**** Professor voluntário do Programa de Pós-Graduação em Sociologia Política da UFSC e coordenador do Núcleo Interdisciplinar em Políticas Públicas (NIPP).E-mail: <seibel@cfh.ufsc.br>.

${ }^{1}$ Este trabalho é produto de projeto de pesquisa "Análise e Avaliação dos Indicadores Educacionais da Região Sul", aprovado em Edital OBEDUC 2011 Observatórios da Educação, Capes/INEP.

${ }^{2}$ É importante esclarecer que os dados dos questionários das edições 2009 e 2011 da Prova Brasil ainda não estavam publicados pelo INEP na ocasião da confecção deste trabalho.

${ }^{3} \mathrm{O}$ questionário professores pode ser acessado em: $<$ http://download.inep.gov. br/educacao_basica/prova_brasil_saeb/questionarios/2013/questionario_professor.pdf $>$. O questionário diretores pode ser acessado em: $<$ http://download. inep.gov.br/educacao_basica/prova_brasil_saeb/questionarios/2013/questionario_diretor.pdf>. 